\title{
Study on the Correlation between Industrial Structure and Economic Growth in Hubei Province
}

\author{
Zheng Wang \\ School of Management, Wuhan University of Technology, Wuhan 430070, China \\ wzheng92@163.com
}

Keywords: Hubei province, Industrial structure, Economic growth, Relevance research.

\begin{abstract}
According to the "Petty - Clark theorem", the highest stage of the development of regional industrial structure presents as the form of "the third, the second and the first", namely the proportion of the third industry's GDP is largest. The data shows that the proportion of Hubei's second industry has the largest contribution to its economic growth and there is an obviously unreasonable trend of development in the industrial structure. From the perspective of industrial structure, using the time series analysis and econometric model, this paper explores the relationship between the change of the industrial structure and regional economic growth, and the third industry and the GDP of Hubei province and finds that the third industry has the most significant effect to the economic growth of Hubei province. On the basis of that, this paper proposes several relevant policy suggestions for the economic development of Hubei province and the optimization of the industrial structure.
\end{abstract}

\section{Introduction}

In 2004, the central authorities put forward the strategy of "the rise of central China" and formally adopted the "plan of promoting the rise of the central region" in 2009. 2014, the State Council issued guidance on relying on the golden waterway to promote the development of the Yangtze River Economic Belt. 2015, the State Council approved the "develop city clusters along the middle reaches of the Yangtze River" plan. Obviously, the development of regional economy in our country has been thinking from the past to rely on Plate economic gradient drive gradually change to rely on economic belt, the coordinated development of economic zones, and the unique geographical position of Hubei makes it occupy an important strategic position in the Yangtze River economic belt and the central urban agglomeration. At present, Hubei province is one of the developed provinces in the middle, but its economy is far behind the developed coastal provinces, Moreover, the industrial structure led by industry is under great pressure on resources and environment. In addition, the Hubei provincial government also made it clear "During the period of "12th Five-Year", our province should build a modern industrial system, which is supported by advanced technology industry, advanced manufacturing industry, modern service industry and modern agriculture". Therefore, whether it is from the inherent requirements of economic development, or policy oriented perspective, the transformation of industrial structure will be the focus of future development in Hubei province.

Foreign scholars have carried out a systematic analysis of the relationship between the total economic output and industrial structure, which is represented by economists such as Howell Chris, Dolfsma Wilfred and G. Petrakos etc. ${ }^{[1-3]}$. Chinese scholars have made a lot of research on China's economic growth, and achieved fruitful results. Chunhui Gan believes when the government formulate the industry structure policy, should break through the restrictive condition that constraints advancement of industrial structure, when emphasize the rationalization of industrial structure, to promote the advancement of industrial structure, give full play to the role of industrial transformation and upgrading promoting the growth of economic ${ }^{[4]}$. Qiusheng Liu using principal component analysis comprehensive evaluate the influence of the change of industrial structure on the quality of economic growth in Jiangsu province, reveals the relationship between the change of industrial structure and economic growth ${ }^{[5]}$. Haojuan Chang analyzed the relationship between economic growth and industrial structure change in China from 1952 to 2011. It was found that the characteristics of economic growth and industrial structure change are different under different 
economic systems ${ }^{[6]}$. Xuefa Lu using dynamic panel GMM Estimation for the robustness test of the national 31 provincial dynamic panel data research results, reveals the causal Grainger relationship and Variation law between the industrial structure change and economic growth ${ }^{[7]}$. Although scholars have done a lot of theoretical and practical research on the relationship between industrial structure and economic growth, these studies rarely consider the imbalance of regional development. As the central province of Hubei, since the reform and opening up the economy has also been developed, but there is a big gap compared with the developed coastal provinces. This paper aims to explore the relationship between industrial structure and economic growth in Hubei Province, and puts forward some countermeasures to promote the long-term and stable economic growth.

\section{The status quo of the industrial structure of Hubei province}

\subsection{Analysis Based on the Proportion of the Output Value of the Three Industries}

After the reform and opening up, the industrial structure of Hubei province has witnessed tremendous changes. As shown in Figure 1, in 1991, the proportion of three industries in Hubei province is $30.6: 39.4: 30.0$, while in 2015, the proportion of three industries in Hubei province is 11.2:45.7:43.1. The industrial structure experienced a qualitative leap. The industrial pattern changed from the form of "the second, the first and then the third" to the form of "the second, the third, and then the first". Over the development of more than twenty years, the first industry has declined by 19.4 percentage points, the second industry has increased by 6.3 percentage points, and the third industry has increased by 13.1 percentage points. Overall, the industrial structure has been optimized, which is consistent with the change rule of China's industrial structure.

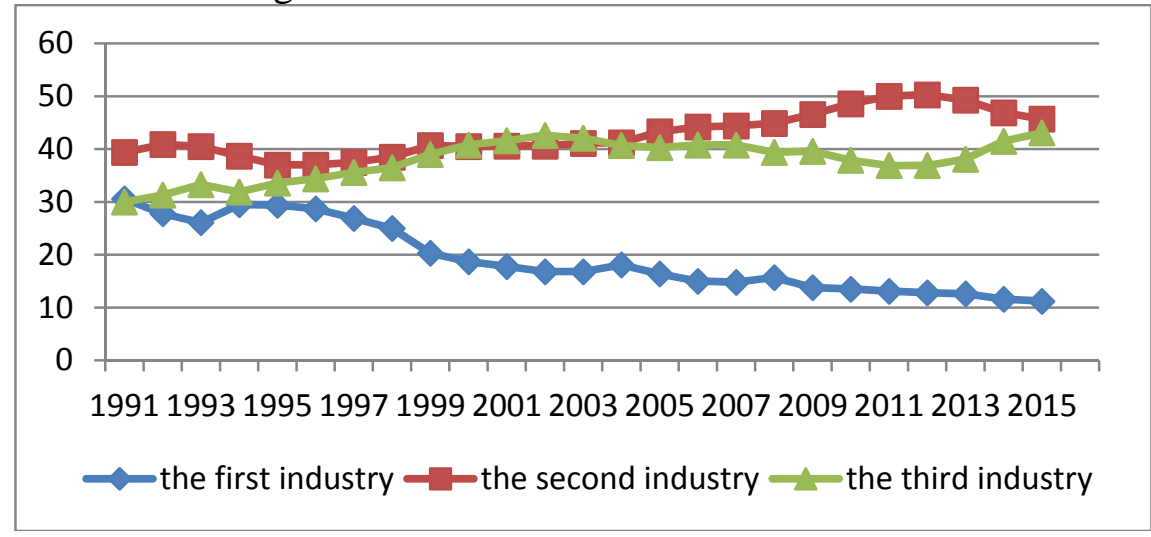

Figure 1. Changes in the proportion of the three industrial output value in Hubei province

\subsection{Analysis Based on the Employment Proportion of the Three Major Industries}

Due to the influence of the industrial structure, the employment proportion of the three major industries in Hubei changes accordingly. As is shown in Figure 2, in the beginning of the nineties, in terms of the employment proportion, the first industry occupies the dominant position in Hubei province. In 1991, the proportion of employment of the first industry is $60.3 \%$, while the total proportion of the second industry and the third industry is only $39.7 \%$. After the development of more than 20 years, there is a great change in the employment proportion of Hubei province. In 2015, the employment proportion of the three major industries is 38.6:23.1:38.3. Comparatively speaking, the employment proportion of the first industry falls more obvious. Generally speaking, in the recent 20 years, there have been some achievements in the adjustment of the industrial structure in Hubei province. The GDP has been increasing steadily. The output values of the three major industries have also been increasing year by year, but the growth rate is not consistent. The industrial structure of the three major industries has changed from the form of "the second, the first, and then the third" to the form of "the second, the third, and then the first", and there has been a rapid development in the third industry. This phenomenon is consistent with the change rule of China's industrial structure, which shows that the industrial structure of Hubei province has been gradually optimized, and meanwhile, the own structures of the three major industries has also been adjusted constantly. The proportion of the third industry is increasing, which shows that the employment structure of Hubei province has been optimized to some extent. In the process of adjustment of industrial structure, the employment 
proportion of the three major industries in Hubei province has undergone tremendous changes. The declining employment proportion of the first industry is roughly equal to the rising employment proportion of the third industry. However, the employment proportion of the first industry employment is still high and the productive efficiency of agricultural is a bit low, which ties up a lot of free labors. Besides, the numbers of employment of the second industry and the third industry are not coordinated with the development of their output values, which need to be further optimized.

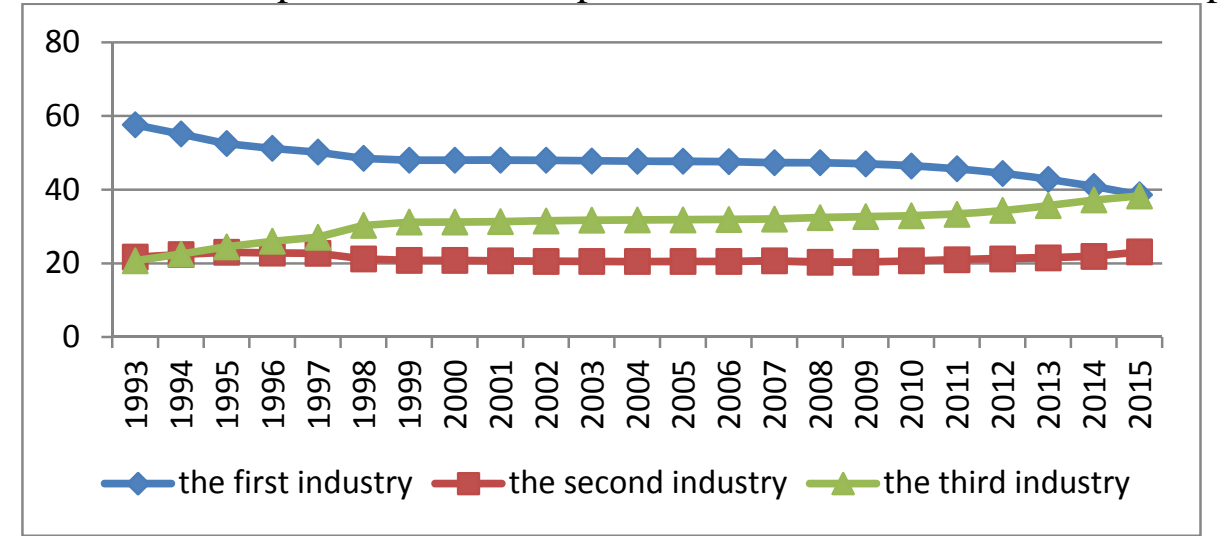

Figure 2. Changes in the proportion of employment in the three major industries in Hubei

\section{Empirical Study}

\subsection{Model Design}

As economic growth depends on the effective allocation of various resources such as labor, capital, and technology and so on, and to a large extent the industrial structure determines the results of resource allocation, so economic growth depends on the state of industrial structure to a certain extent. In this paper, we use the time-series data from 1991 to 2015 to study the causal relationship between industrial structure adjustment and economic growth in Hubei Province, and measure the contribution of the three industries to regional economic growth.

Assuming that the functions of different industrial structures have a function of $Y=F(X 1, X 2$, $\mathrm{X} 3, \mathrm{~A})$, Where $\mathrm{Y}$ represents regional gross domestic product. $\mathrm{Xi}$ represents the proportion of the output value of the i industry to the total output value, $i=1,2,3$, and A represents the economic system and the technical level. The function is differentiated and both ends are divided by $\mathrm{Y}$ at the same time:

$$
\frac{d Y}{Y}=\frac{X_{1}}{Y} \frac{\partial Y}{\partial X_{1}} \frac{d X_{1}}{X_{1}}+\frac{X_{2}}{Y} \frac{\partial Y}{\partial X_{2}} \frac{d X_{2}}{X_{2}}+\frac{X_{3}}{Y} \frac{\partial Y}{\partial X_{3}} \frac{d X_{3}}{X_{3}}+\frac{A}{Y} \frac{\partial Y}{\partial A} \frac{d A}{A}
$$

Mark $^{\beta_{i}}=\frac{X_{i}}{Y} \frac{\partial Y}{\partial X_{i}}, \beta_{0}=\frac{A}{Y} \frac{\partial Y}{\partial A} \frac{d A}{A}$ to (1) both sides take logarithm at the same time can be written as:

$$
\log Y=\beta_{0}+\beta_{1} \log X_{1}+\beta_{2} \log X_{2}+\beta_{3} \log X_{3}+\varepsilon
$$

\subsection{Data Analysis}

Combined with the data provided in the Hubei Statistical Yearbook (1992-2016), and the use of Eviews8.0 to operate, we can get the return of Hubei Province's gross national product (GDP) Y to the proportion of the three industries. The constant term $\mathrm{p}$ in the regression equation is less than 0.05 , accept the original hypothesis and remove the constant term.

$$
\begin{array}{llll}
\log Y=-1.616352 \log X_{1}+3.964925 \log X_{2}+0.8333757 \log X_{3} \\
S\left(\hat{\beta}_{i}\right)= & 0.200565 & 0.650578 & 0.678874 \\
\mathrm{t}= & -8.059010 & 6.094464 & 1.228147 \\
R^{2}=0.879292 & \bar{R}^{2}=0.867221 & S \cdot E=0.351929 & \mathrm{D} . \mathrm{W}=0.522824
\end{array}
$$

For the regression model, the model $\mathrm{R}^{2}=0.879292$ shows that the model is better to fit, the first industry output value increased by $1 \%$ will make the national GDP in Hubei Province decreased by 
$1.616352 \%$, the proportion of the second industry output value increased by $1 \%$ will make the total production of Hubei Province Value increased by 3.964925\%, the proportion of tertiary industry output value increased by $1 \%$ will increase the gross national product of Hubei Province $0.833757 \%$.

\subsection{Model Test}

(1) Significance test. Taking $\alpha=0.05$ checks the critical value of freedom of n-k-1=19 is $t_{0.025}(19)$ $=1.729$, the probability of X1, X2, X3 corresponding to the t statistic is $-8.059010,6.094464$, 1.228147, the first and second industry to meet the requirements, which shows that under the $5 \%$ significance level, the slope coefficient is not zero, indicating that the increase in the proportion of the first and second industries has a significant impact on national economic growth.

(2) Heteroscedasticity test. For heteroscedasticity, the White test is used. The original hypothesis model is the same as the variance, according to the White test results, because $\mathrm{nR}^{2}=6.97054$, and below 0.05 significance level $\chi_{0.05}(3)=7.81$, obviously, should accept the original hypothesis, that is, the model with the same variance, there is no heteroscedasticity problem.

(3) Sequence correlation test. The model does not have constant terms, so we can't determine the existence of sequence-related problems by the value of D.W, so in this paper, we use the Lagrange multiplier (LM) method to test the residual sequence of (3). The probability is 0.0001 , the probability of $\mathrm{nR}^{2}$ is 14.58045 , the probability is 0.0007 , and the probability is 0.0001 , the probability is 0.0007 , the probability is 0.0007 , so it should accept the original hypothesis, that is, the model does not exist sequence correlation. Similarly, when $\mathrm{P}=1,3$, there is no sequence correlation.

\section{Conclusion}

(1) There is a long-term stable relationship between industrial structure and economic growth. Changes in industrial structure are not smooth, but in the long run there is a kind of economic mechanism that makes the industrial structure and economic growth share a random changing trend, and the policy about controlling the economic growth by adjusting and optimizing the industrial structure in Hubei Province.

(2) It is the second industry that makes the most contribution to economic growth. The tertiary industry's output value and economic growth have a same direction changing relationship and the Influence elasticity is big, which means tertiary industry has great potential of development, and expanding the proportion of regional GDP of the tertiary industry will promote the healthy growth of the economy.

(3) Under the same conditions, the growth of the proportion of the second and third industries in Hubei Province will have a positive effect on GDP, while the proportion of the first industry will have a secondary effect on GDP. According to the theory of industrialization stage, with the development of economy, the proportion of the primary industry in the whole national economy will be smaller and smaller, so the negative effect relationship between the first industry and GDP in Hubei Province is consistent with the objective laws; As the industry input and output are not coordinated, the positive effect on GDP is not very strong.

\section{Suggestions}

(1) Paying more attention to the development of primary industry and speeding up the upgrading of agricultural industry. Agriculture is the basis of the people, and to consolidate the status of agriculture, it is important to pay attention to the development of the primary industry, stimulate the enthusiasm of farmers, develop appropriate policies to adjust the rural industrial structure and vigorously develop agriculture with characteristics of Hubei, in particular the development of green food and local specialties, which make the adjustment of agricultural structure with minimal investment and the greatest comprehensive benefits, and ultimately to optimize the upgrading of agricultural industry structure.

(2) Adjusting the proportion of the secondary industry and promoting the industrialization process. Secondary industry is the leading industry in the Hubei area industrial structure. The main industry 
sector of the secondary industry is heavy industry. Compared with the tertiary industry as the leading industrial in the developed areas, the industrial structure in Hubei is irrational. In that case, Hubei region should change the situation that the proportion of heavy industry is too big. While strengthening the advantages of industry, we also need to focus on the support of new industries, change the traditional way of industrial growth, form the industrial clusters, and achieve the optimization and upgrading of regional industrial structure in Hubei.

(3) Speeding up the technological innovation and vigorously developing the tertiary industry. The tertiary industry in Hubei Province has developed steadily and the emerging service industry has developed slowly. It is necessary to establish a sound market system, introduce the advanced science and technology, use the information technology to develop the tertiary industry, promote the growth mode to change from extensive type to agglomeration type and achieve the optimization and upgrading of the entire industrial structure.

\section{Acknowledgements}

This paper is supported by National Social Science Foundation of China (Grant No.15ZDC022).

\section{References}

[1]. Howell Chris. The British Variety of Capitalism: Institutional Change, Industrial Relations and British Politics[J]. Science, 2007, 07: 239-263

[2]. Dolfsma Wilfred, Verburg Rudi. Structure, Agency and the Role of Values in Processes of Institutional Change[J]. Science, 2008, 12: 1031-1054

[3]. D. Kallioras, G. Petrakos. Industrial growth, economic integration and structural change: evidence from the EU new member-states regions[J]. Science, 2010, 12: 667-680

[4]. Chunhui Gan, Ruogu Zheng. An Empirical Study on the Effects of Industrial Structure on Economic Growth and Fluctuations in China[J]. Economic Research Journal, 2011, 05: 4-31.

[5]. Qiusheng Liu, Xuejiao Liu. The Effects of Industrial Structure Change of Jiangsu Province on Its Economic Growth Quality[J]. Commercial Research, 2013, 12: 15-20.

[6]. Haojuan Chang. An Empirical Study on the Effects of Industrial Structure on Economic Growth of Our Country[J]. Science and Technology Management Research, 2014, 07: 110-114.

[7]. Xuefa Lu, Chuanzhong Du. the Change of Industrial Structure and Economic Growth in the New Normal: a Generalized Moment Estimation Based on Dynamic Panel Data [J]. Modernization of Management, 2015, 06: 19-21. 